Full length article

\title{
Maximizing social outcomes? Social zapping and fear of missing out mediate the effects of maximization and procrastination on problematic social networks use
}

\author{
Silke M. Müller ${ }^{\mathrm{a}, \mathrm{b}, *}$, Elisa Wegmann ${ }^{\mathrm{a}}$, Dario Stolze ${ }^{\mathrm{a}}$, Matthias Brand ${ }^{\mathrm{a}, \mathrm{b}}$ \\ ${ }^{\text {a }}$ Department of General Psychology: Cognition and Center for Behavioral Addiction Research (CeBAR), University of Duisburg-Essen, Duisburg, Germany \\ ${ }^{\mathrm{b}}$ Erwin L. Hahn Institute for Magnetic Resonance Imaging, Essen, Germany
}

\section{A R T I C L E I N F O}

\section{Keywords:}

Social networking

Online communication

Internet addiction

Social networks use disorder

SNS addiction

Structural equation modeling

\begin{abstract}
A B S T R A C T
The ubiquity of internet-capable mobile devices enables individuals to use online communication and social networking sites (SNSs) almost anytime and anywhere, which may foster addictive usage patterns. SNSs provide manifold options and suggestions for social contacts and experiences, which can increase social comparison processes that potentially cause negative affective states, such as envy, dissatisfaction, or fear of missing out (FoMO). This empirical study ( $N$ 226) investigates associations between the tendencies to maximize outcomes and to procrastinate and problematic social networks use. We assume socially driven cognitions such as FoMO and the tendency to switch or cancel appointments at short notice, named "social zapping," to mediate these effects. We tested the hypothesized effects through structural equation modeling. The results confirm positive associations between the mentioned constructs. Procrastination fully mediated the effect of maximization on problematic social networks use. Furthermore, FoMO mediated the effects of both maximization and procrastination. The findings indicate that tendencies to maximize and to procrastinate lead to problematic SNS use, especially in cases where specific fears and intentions to find/to not miss a potentially "better" alternative for social experiences are high. Potential relationships and reinforcement mechanisms in the developmental process of problematic social networks use are discussed.
\end{abstract}

\section{Introduction}

Since the evolution of Web 2.0, social networking has been the core of the 21st century's online activities. The ubiquity of internet-capable mobile devices enables individuals to use social networking sites (SNSs) frequently and in nearly every situation in daily life. Thus, in addition to the positive and gratifying experience of social contact, online social networks are highly available, which fosters problematic and addictive usage patterns (Salehan \& Negahban, 2013). In the context of problematic social networks use, researchers have emphasized the relevance of specific predisposing factors, such as personality traits, psychopathological constitution, and negative consequences associated with SNS overuse. However, studies that have investigated moderation or mediation effects between predisposing variables and potential reinforcing mechanisms have been underrepresented even though they have been assumed to be crucial for developing tendencies toward problematic social networks use (Wegmann \& Brand, 2019). This study investigates whether the effects of specific traits (i.e., maximization and procrastination) are mediated by specific socially driven cognitions (i.e., FoMO and the willingness to cancel appointments in favor of supposedly better alternatives, named "social zapping") in explaining problematic social networks use.

The use of SNSs and online communication applications, such as Facebook, Instagram, or WhatsApp, is mainly socially motivated with intentions such as staying in contact or communicating with friends and searching for individuals and social activities (Kuss \& Griffiths, 2011). Online social interaction offers more distant, more anonymous, and less direct social contact compared with face-to-face communication. This phenomenon is advantageous for certain individuals, for example, shy and socially anxious individuals who can become and remain socially

\footnotetext{
* Corresponding author. University of Duisburg-Essen General Psychology: Cognition and Center for Behavioral Addiction Research (CeBAR), Forsthausweg 2, 47057, Duisburg, Germany.

E-mail addresses: silke.m.mueller@uni-due.de (S.M. Müller), elisa.wegmann@uni-due.de (E. Wegmann), dario.stolze@uni-due.de (D. Stolze), matthias.brand@ uni-due.de (M. Brand).
} 
connected (Baker \& Oswald, 2010; Orr et al., 2009; Pierce, 2009), and could improve life satisfaction (Dienlin, Masur, \& Trepte, 2017). SNSs can be used actively, for example, by creating content and posting messages, but the use is often passive, for example, viewing content, reading posts of others, searching information/events/individuals, or scrolling through timelines to pass time. SNSs offer a continuous stream of information that provides users with a variety of opportunities for social comparison and new/alternative options. Not surprisingly, studies have demonstrated that (especially passive) SNS usage is linked to increased social comparison and negative affective states such as envy and jealousy (Appel, Gerlach, \& Crusius, 2016; Muise, Christofides, \& Desmarais, 2009; Verduyn et al., 2015; Wallace, James, \& Warkentin, 2017). Some assume a loop in a manner that SNSs offer easy access to socially relevant information, which despite emerging negative affective states, promotes increased SNS use (Muise et al., 2009). Situational envy and jealousy are when individuals have thoughts regarding having missed out on something meaningful or not having chosen the best possible (social) option. We assume that individual traits and cognitive states associated with such thoughts (e.g., the fear of missing out on an even better social opportunity) promote more frequent SNS use, which increases social comparison opportunities and thus may be a reinforcement mechanism to develop addiction-like symptoms.

This study focuses on maximization and procrastination as traits that represent a general tendency to strive for the best possible options and (thereby) delay decisions and on state variables (i.e., online FoMO and so-called social zapping tendencies) potentially promoting problematic social networks use. In addition to the already established construct of FoMO, this study investigates the tendency to switch social appointments as a socially deviant component that might additionally contribute to a problematic (rather than excessive) use of SNSs. The relationships assumed are analyzed through correlation analyses (in the first step) and structural equation modeling (in the second step) to test the mediating effects. In the following, the mentioned constructs and their possible relations are described in more detail.

\subsection{Problematic social networks use}

Problematic social networks use is characterized by an ongoing use of (one or more) SNSs or online communication applications such as instant messenger services, blogs, and microblogs despite negative consequences in daily life such as conflicts with friends or family that are independent of the device or application used (Montag et al., 2018; Wegmann \& Brand, 2016). Depending on the type and focus of research, the phenomenon has also been referred to as "social networks use disorder," "Facebook addiction," "Internet-communication disorder," or "smartphone addiction" (Guedes, Nardi, Guimarães, Machado, \& King, 2016; Wegmann, Müller, Ostendorf, \& Brand, 2018). Although most of the literature on problematic smartphone use has focused on the use of SNSs and online communication applications through smartphones, we prefer a device-independent terminology because problematic smartphone use could also result from activities other than the use of social networks (e.g., gaming, shopping, information search) and also because social networks can be used through other devices (e.g., tablets or laptops).

Problematic social networks use is not classified as a mental disorder, but an increasing number of empirical studies have supported the view that it can cause symptoms similar to those of substance-use disorders and other addictive behaviors (for reviews see Kuss \& Griffiths, 2017; Wegmann et al., 2018). Accordingly, the symptoms assumed for problematic social networks use follow those of related disorders, such as gambling disorder and gaming disorder, both of which will be included in the upcoming ICD-11 as disorders due to addictive behaviors (World Health Organization, 2019). The symptoms include an increase in preferring the behavior over other (social) activities, impaired control over the behavior, and the continuous use despite negative consequences. The behavioral pattern is beyond excessive use (usage time is not a criterion), and the use must lead to significant functional impairment in personal, social, educational, or other domains of life to be termed problematic or addictive (World Health Organization, 2019).

In their review, Kuss and Griffiths (2017) mention types of models that propose predictive factors and mechanisms that potentially contribute to the development of problematic social networks use and problematic Internet use in general. The cognitive-behavioral model (Davis, 2001) assumes that maladaptive cognitions in combination with external reinforcing factors result in problematic use of SNSs. The social-skill model (Caplan, 2005) suggests that deficits in social skills lead to a behavioral pattern in terms of preferring online over face-to-face social interactions, which if additionally reinforced by reward experiences, promotes problematic social networks use. According to the social-cognitive model (LaRose, Lin, \& Eastin, 2003), problematic usage behavior results from the expectation of rewarding outcomes (e.g., social networking will relieve loneliness) in combination with high self-efficacy and low control over the use.

Another argument is that the use of SNS offers many options for immediate rewards that promote increased usage (Wegmann \& Brand, 2019), increasing problems in everyday life (e.g., neglect of offline relationships). Negative mood and depressive states resulting from these problems are counteracted by continued SNS use, which could lead to a vicious cycle (Griffiths, Kuss, \& Demetrovics, 2014). These cyclic relationships are also in line with recent neurocognitive models on behavioral addictions, such as the I-PACE model (Brand et al., 2019). This model suggests interactions between individual characteristics and cognitive and affective components in the development and maintenance of specific Internet use disorders (cf. Brand, Young, Laier, Wolfling, \& Potenza, 2016) and addictive behaviors in general.

\subsection{Maximization and procrastination as possible predictors}

One of individuals' core characteristics specifically linked to an overuse of SNSs might be maximization tendencies. Maximization has been most commonly conceptualized as a personality trait that represents the tendency to strive for the best choice (for reviews see Cheek \& Schwartz, 2016; Misuraca \& Fasolo, 2018). The individual maximizing tendency was shown to be a trait that appears stable across different domains (Kokkoris, 2019); however, most of the existing literature derives from the field of consumer research and otherwise appears fragmented (Misuraca \& Fasolo, 2018). Schwartz et al. (2002) propose that "maximizers" (compared with "satisficers") consistently aim to choose the best of all available options and thus tend to search for more gratifying alternatives. Therefore, maximizers perform a more extensive search of information and make more thorough comparisons of options, which paradoxically results in less satisfaction with the choices made and higher feelings of regret (Iyengar, Wells, \& Schwartz, 2006; Schwartz et al., 2002). Furthermore, to find the "best" option, maximizers tend to worry about the completion of their information search and tend to delay or avoid decisions (Parker, Bruine de Bruin, \& Fischhoff, 2007; Spunt, Rassin, \& Epstein, 2009). Accordingly, positive associations between maximization and (decisional) procrastination tendencies are reported (Parker et al., 2007; Turner, Rim, Betz, \& Nygren, 2012). Therefore, we hypothesize that maximization predicts procrastination.

Furthermore, a high maximization tendency can be considered a dysfunctional decision-making style. Parker et al. (2007) find the maximizers are more likely to demonstrate problematic decision-making styles. Furthermore, contrary to the positive correlations with the tendency to avoid decisions, maximizers tended toward impulsive decision-making. Similarly, addictive behaviors are assumed to result from impaired decision-making because of a predominance of impulsive (over reflective) decision processes in favor of options that offer high immediate gratification (e.g., Bechara, 2005). Similar to maximization, procrastination is considered a dysfunctional decision-making style (Ferrari \& Dovidio, 2000). 
Procrastination is described as the tendency to delay or avoid decisions or tasks to an extent that causes negative outcomes (Tuckman, 1991). Instead of engaging in an intended but potentially aversive task, procrastinators tend to provide in to short-term temptations. Such temptations offer immediate gratification for procrastinators, such as satisfaction of the need for relatedness through Facebook use (e.g., Reinecke, Vorderer, \& Knop, 2014). Several lines of research have suggested that the Internet, and specifically SNSs, are frequently used for procrastination purposes. In a study by Lavoie and Pychyl (2001), over half of the participants reported frequent procrastination online. Thereby, Internet procrastination (also referred to as or "cyberslacking" or "cyberloafing" (e.g., Blanchard \& Henle, 2008)) was positively correlated with trait procrastination. Davis, Flett, and Besser (2002) conceptualize procrastination as a key aspect of problematic Internet use. Accordingly, positive correlations between procrastination and symptoms of problematic Internet use are reported (Geng, Han, Gao, Jou, \& Huang, 2018). This association is further underlined by similarities in individual characteristics related to both constructs. Studies on clinical and non-clinical samples have demonstrated that decisional procrastination (also called indecisiveness) is associated with psychopathological symptoms including depression and anxiety (Frost \& Shows, 1993; Rassin \& Muris, 2005; Rassin, Muris, Franken, Smit, \& Wong, 2007), which are also associated with problematic Internet use (Ho et al., 2014). A more present-oriented and less future-oriented time perspective is associated with trait procrastination (Sirois, 2014) and increases the risk of (state) procrastination and problematic Internet use because of a lack of self-control (Kim, Hong, Lee, \& Hyun, 2017).

In the special context of problematic social networks use, studies on predictive effects of trait procrastination have been relatively rare. Przepiorka, Błachnio, and Díaz-Morales (2016) demonstrate general and decisional procrastination to predict symptoms of problematic Facebook use. Rozgonjuk, Kattago, and Taht (2018) demonstrate a significant relationship between procrastination and what they call "problematic smartphone use" in university students, which was mediated by social media use. Other studies have focused on the motive for using SNSs for procrastination purposes. For example, the use of SNSs (in this case Facebook) for procrastination was demonstrated to have detrimental effects on students' well-being (Meier, Reinecke, \& Meltzer, 2016). Based on their review, Ryan, Chester, Reece, and Xenos (2014) highlight that further research is necessary, but that an assumption might be that "the gratification of passing time" (p. 136) is associated with problematic SNS use. The aforementioned findings lead us to the hypothesis that maximization and procrastination predict symptoms of problematic social networks use. Fig. 1 presents these relationships and other assumed relationships between the mentioned constructs.

\subsection{Social zapping and FoMO as possible mediators}

The mentioned special characteristics of online communication (e.g., more distant, more anonymous, and less direct social contact) facilitate socially undesirable behaviors, such as Internet harassment, cyberbullying, or hate speech, which have a much larger range online compared with their offline equivalents (Patchin \& Hinduja, 2006; Slonje \& Smith,
2008; Wolak, Mitchell, \& Finkelhor, 2007). Another aspect facilitated by online compared with offline communication is spontaneous cancellations of appointments. In a representative study commissioned by an international travel portal (lastminute.de, 2012), 7200 Europeans in representative samples from Great Britain ( $n$ 2103), Ireland ( $n$ 1007), Germany ( $n$ 1066), France ( $n$ 1010), Italy ( $n$ 1010), and Spain ( $n$ 1010) were asked online about their cancellation behavior. The findings demonstrate that at a rate of more than once per second, a European (54\%) cancels her or his appointments with friends if a short-term alternative is supposed to offer greater benefits. They termed this behavior "social zapping." The term "zapping" is derived from the verb "to zap" (German: "zappen"), meaning "to change television channels using a remote control" ("Zap," n. d.), which is commonly referred to as "channel-surfing" in United States' English. Thus, in an analogy, social zappers are assumed to switch between social contacts or appointments in a similar manner to how television viewers switch between television channels. According to our review of the literature, this tendency has not been studied scientifically. In this study, we aim to introduce the construct of social zapping and to report the first empirical data on its potential role in the context of social networks use. In addition to the assumption that spontaneous cancellations can be easily realized through online messaging, the socially deviant character of this behavioral tendency can be assumed to contribute to a usage that is problematic in terms of causing negative consequences, for example, in social life. Notably, we apply the following working definition to our research: Social zapping is the tendency to cancel or switch between social appointments at the last minute in favor of alternatives that are supposedly more beneficial.

We assume that social zapping behavior relates to the tendency to maximize social experiences. Related studies have investigated maximization tendencies in the context of social relationships. Mikkelson and Pauley (2013) find that maximization is correlated with less satisfaction, less investment, and less commitment in personal relationships. Furthermore, they report that maximization is associated with a greater awareness of relationship alternatives. All of these factors, namely, being less satisfied and less committed to relationships and being more aware of alternative personal relationships, likely contribute to social zapping behavior. The short-term nature of social zapping behavior can be attributed to decisional procrastination in terms of postponing the cancellation of appointments until the last minute. Procrastinators tend to start tasks at the last minute, even if an early completion was intended (Lay \& Burns, 1991; Pychyl, Morin, \& Salmon, 2000). Accordingly, we expect maximization and procrastination tendencies to predict social zapping behavior (Fig. 1).

Furthermore, associations can be assumed between the social zapping tendency and negative consequences resulting from problematic SNS use. Social zapping behavior incorporates a preference for short-term reward alternatives by neglecting long-term risks, for example, losing friendships. Thus, by definition, social zapping likely has detrimental effects on offline social relationships, and thus on psychological well-being. Consistently, Newman, Schug, Yuki, Yamada, and Nezlek (2018) demonstrate that maximizing in selecting friends (which is similar to social zapping) is associated with decreased life satisfaction

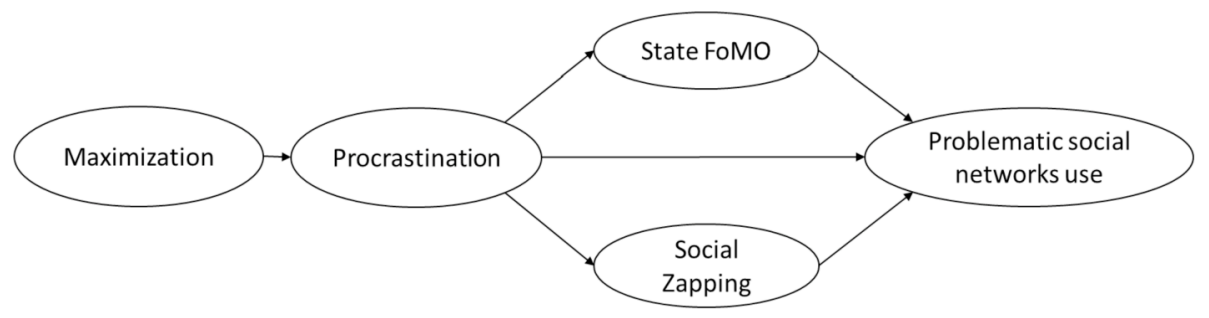

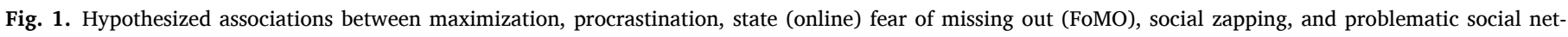
works use. 
and lower self-esteem and with increased negative affect. Furthermore, the authors report that maximizers faced with many (compared with few) choice options concerning potential friends showed an increased likelihood of negative consequences in terms of regret and further diminished well-being (Newman et al., 2018). SNSs and social media offer such many options, which might lead those individuals who tend to maximize social relationships, namely, social zappers, to suffer from increased negative consequences of SNS use.

Furthermore, decisional procrastinators (i.e., indecisives) were demonstrated to have a higher proneness toward distractions (Harriott, Ferrari, \& Dovidio, 1996). Social zappers, who we assume procrastinate (online) to maximize social experiences, may easily be distracted by alternate options that supposedly offer higher gratification. SNSs are an easy means to find such potentially more gratifying social experiences by offering many opportunities and recommendations for social contacts or events. However, the frequency and variety of social alternatives may, in turn, increase dissatisfaction and negative affective outcomes in maximizers (and hence, in social zappers), which may be coped with by even more extensive use of social networks - a mechanism that might keep some individuals stuck in SNSs (c.f. Griffiths et al., 2014). Accordingly, we assume a mediating role of social zapping (Fig. 1).

Similar to maximization, high FoMO has been found to produce higher levels of regret and other negative affective outcomes and plays a central role in the context of problematic mobile phone and SNS use (Caplan, 2006; Oberst, Wegmann, Stodt, Brand, \& Chamarro, 2017; Wegmann, Oberst, Stodt, \& Brand, 2017). FoMO is defined as the "pervasive apprehension that others might be having rewarding experiences from which one is absent" (Przybylski, Murayama, DeHaan, \& Gladwell, 2013, p. 1841). Although FoMO appears in contexts other than in the online world, an assumption is that social media might increase feelings of FoMO because it provides many, frequent reminders of alternative (potentially more gratifying) social experiences that an individual might miss (Milyavskaya, Saffran, Hope, \& Koestner, 2018). The authors further draw on similarities between FoMO and maximization by stating: "Similarly, FOMO can be thought to arise from an abundance of choices among activities or experiences, particularly those of a social nature, coupled with an uncertainty over the 'best' choice and anticipatory regret over the options not selected." (Milyavskaya et al., 2018, p. 725 f.). Accordingly, we assume that the tendencies toward maximization and procrastination predict the severity of experienced FoMO when online, referred to as online-specific FoMO or state FoMO (Wegmann et al., 2017).

Furthermore, we assume a circular relationship because individuals may also use SNSs and social media to cope with negative feelings caused by FoMO, for example, by posting about a fun activity to make oneself feel better (Milyavskaya et al., 2018). Thus, state FoMO may serve as a mediator between the maximizing (and procrastination) tendency and problematic social networks use. Studies on the relation between individual predisposing factors, FoMO, and SNS use have indicated a mediating role of FoMO. For example, FoMO has been demonstrated to mediate the effect of psychopathological symptoms (anxiety and depression) on problematic SNS use (Dempsey, O'Brien, Tiamiyu, \& Elhai, 2019; Oberst et al., 2017). Earlier, Przybylski et al. (2013) find that FoMO mediates relations between deficits in need satisfaction and increased social media use in adolescents. Additionally, FoMO and boredom proneness - a construct related to decisional procrastination (Ferrari, 2000) - have been found to serially mediate the effects of depression and anxiety symptoms on pathological smartphone use (Wolniewicz, Rozgonjuk, \& Elhai, 2019). Wegmann et al. (2017) investigate the role of state FoMO and confirmed its mediating effect on the relationship between psychopathological symptoms and problematic social networks use. Similarly, we expect FoMO to mediate the effects of maximization and procrastination on the tendency toward problematic social networks use (Fig. 1).

To summarize, we assume that individual traits associated with tendencies to procrastinate looking for better options (maximization and procrastination) promote dysfunctional SNS use. This association might be mediated by specific states associated with thoughts and feelings of potentially missing out on something meaningful or not having chosen the best possible option (state FoMO and social zapping), which may be coped with by even more social networks use, which increases opportunities for social comparison and respective mechanisms. Accordingly, the tendency not to want to miss out on potentially better alternatives for social interaction may reinforce a dysfunctional, uncontrolled use of SNS, resulting in higher symptoms of problematic social networks use. The hypothesized relationships between maximization, procrastination, social zapping, state FoMO, and problematic social networks use are presented in Fig. 1. We test the hypothesized associations through correlation analyses and structural equation modeling.

\section{Methods}

\subsection{Participants}

In this study, we investigated 226 participants (135 females, 91 males) aged between 17 and 37 years, $M \quad 22.00, S D \quad 3.30$. Most of the participants $(71.2 \%)$ were students, $13.7 \%$ were employees, and $12.3 \%$ were trainees or pupils. Overall, $77.2 \%$ reported having a general qualification for university entrance as the highest educational level, $9.3 \%$ had a university/college degree, and $13.4 \%$ had another schoolleaving graduation. Regarding the distribution of problematic social networks use, 153 participants (67.7\%) scored non-problematic, 43 participants (19.0\%) scored at risk, and 30 participants (13.3\%) scored problematic, according to the proposed non-diagnostic cutoffs for the short Internet Addiction Test (Pawlikowski, Altstotter-Gleich, \& Brand, 2013; see section 2.2.5). This non-clinical, convenient sample was recruited by mailing lists and contact lists of the University of Duisburg-Essen. The study was conducted individually in a laboratory setting. All participants provided written informed consent for participation. The study was approved by the local ethics committee of the division of Computer Science and Applied Cognitive Sciences at the Faculty of Engineering (University of Duisburg-Essen) in accordance with the Declaration of Helsinki.

\subsection{Instruments}

\subsubsection{Maximization Scale}

We used the Maximization Scale (Schwartz et al., 2002) in a German translation (Greifeneder \& Betsch, 2006) to measure the individual maximizing tendency. The sale comprises 13 items (e.g., "I never settle for second best.") answered on a nine-point Likert scale from 1 disagree to 9 agree. The arithmetic mean of all items serves as a measure of individual maximizing tendency. Cronbach's $\alpha$ was 0.724 .

\subsubsection{Pure Procrastination Scale (PPS)}

The translated PPS (Steel, 2010; Svartdal et al., 2016) was used to measure the individual tendency to delay decisions or tasks. The PPS conforms to three factors (i.e., decisional, behavioral, and timeliness), which correspond to the three scales from which the 12 items of the PPS were selected: the Decisional Procrastination Scale (Mann, Burnett, Radford, \&amp; Ford, 1997; PPS items 1-3), the General Procrastination Scale (Lay, 1986; PPS items 4-8), and the Adult Inventory of Procrastination Scale (McCown, Johnson, \& Petzel, 1989; PPS items 9-12). The PPS was demonstrated to represent each sub facet as accurately as the respective original scale (Svartdal \& Steel, 2017). Each of the 12 items must be answered on a five-point Likert scale from 1 to 5, with higher scores indicating stronger agreement. The three subscales revealed acceptable to excellent consistencies (Cronbach's $\alpha$ for PPS decisional, PPS behavioral, and PPS timeliness was 0.799, 0.921, 0.699, respectively). The respective means of each subscale were used to represent a latent dimension of procrastination. 
Table 1

Unstandardized and standardized estimates of CFA for the SZS.

\begin{tabular}{|c|c|c|c|c|c|}
\hline No. & Item & Latent construct & B & $\beta$ & S.E. \\
\hline 1 & $\begin{array}{l}\text { Kurz vor einer Verabredung überlege ich, ob ich jemand anderen treffen konnte, mit dem ich mehr Spa } \beta \text { hatte. } \\
\text { [Right before an appointment, I consider meeting somebody else with whom I could have more fun.] }\end{array}$ & intentional & 1.000 & 0.778 & 0.045 \\
\hline 3 & $\begin{array}{l}\text { Manchmal wird mir kurz vor einer Verabredung klar, dass ich mich eigentlich lieber mit einer anderen } \\
\text { Person treffen würde. [Sometimes, I realize shortly before an appointment that I'd rather meet } \\
\text { up with someone else.] }\end{array}$ & intentional & 1.270 & 0.662 & 0.051 \\
\hline 5 & $\begin{array}{l}\text { Beim Chatten mit einer Verabredung halte ich zeitgleich nach besseren Optionen Ausschau. } \\
\text { [While texting with somebody I arranged to meet, I keep on looking for better options.] }\end{array}$ & intentional & 1.100 & 0.671 & 0.049 \\
\hline $2(\mathrm{R})$ & $\begin{array}{l}\text { In der Regel halte ich mich a meine Zusagen für Verabredungen. [I usually stick to my } \\
\text { commitments to appointments.] }\end{array}$ & behavioral & 1.000 & 0.528 & 0.061 \\
\hline 4 & Ich sage haufig Verabredungen ab. [I often cancel my appointments.] & behavioral & 1.556 & 0.808 & 0.050 \\
\hline 6 & Ich andere meine Verabredungen oft spontan. [I often rearrange my appointments spontaneously.] & behavioral & 1.387 & 0.637 & 0.055 \\
\hline
\end{tabular}

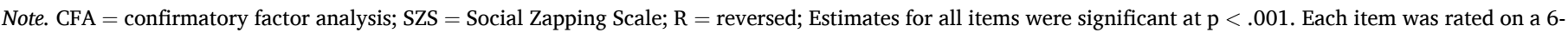
point Likert scale from 1 Trifft überhaupt nicht zu [completely disagree] to 6 Trifft vollkommen zu [completely agree].

\subsubsection{Fear of Missing Out Scale}

To measure online-specific FoMO, we used the scale introduced by Wegmann et al. (2017). The scale is based on the original 10-item Fear of Missing Out Scale (Przybylski et al., 2013), which has been modified and supplemented with items that referred to FoMO in the online context (e. g., "I am continually online, to not miss out on anything.") to be answered on a five-point Likert scale (1 completely disagree to 5 completely agree). The 12 items of the scale load on two factors, namely, trait FoMO (five items) and online-specific state FoMO (seven items). In this study, we used the mean of the state FoMO subscale (Cronbach's $\alpha$ 0.800).

\subsubsection{Social Zapping Scale (SZS)}

To measure social zapping, defined as the tendency to cancel or switch social appointments at the last minute, we created the SZS. In the first step, several statements were formulated with one half representing social zapping intentions and the other half representing actual social zapping behavior. The statements were presented to nine judges (postdoctorates, graduate, and advanced undergraduate students majoring in psychology) who were asked to examine each item and indicate the perceived comprehensibility, clarity, and fit to our understanding of social zapping intentions and behavior, respectively. Based on the judgments, six statements remained with which we were reasonably confident that our understanding of what the statements represent would match to that of the participants, that is, that our measure had face validity.

The final SZS comprised six items representing a behavioral and an intentional component (three items each, e.g., "I often make spontaneous changes of appointments" [behavioral] or "Shortly before an appointment, I think about meeting somebody else, I could have more fun with." [intentional]). Participants were supposed to state their degree of approval on a six-point Likert scale (1 completely disagree to 6 completely agree). All items of the SZS (in the German original and the English translation) are shown in Table 1.

Confirmatory factor analysis (CFA) was performed on the current sample to confirm the hypothesized two-factorial structure. The results of CFA confirmed the conceptualized two-factor solution for the SZS measuring social zapping tendencies, with adequate model fit indices: $\chi^{2}$ (8) $\quad 12.869, p \quad .116$; root mean square error of approximation (RMSEA) 0.052; comparative fit index (CFI) 0.983; Tucker-Lewis Index (TLI) 0.968; standardized root mean square residual (SRMR)

0.030. The internal consistency was acceptable for the overall SZS (Cronbach's $\alpha$ 0.770) and for the two subscales (SZS intentional: Cronbach's $\alpha$ 0.724; SZS behavioral: Cronbach's $\alpha$ 0.699). The standardized and unstandardized parameter estimates are shown in Table 1.

\subsubsection{SNS-specific short Internet Addiction Test (sIAT_SNS)}

The tendency toward problematic social networks use was measured with the German version of the short Internet Addiction Test specified for SNSs and online communication applications (sIAT_SNS; Wegmann, Stodt, \& Brand, 2015). In the instructions, a definition and examples of social networks use were provided including the active and passive usage of SNSs (e.g., Facebook), messaging services (e.g., WhatsApp), blogs, and microblogs. Participants were asked to rate 12 items on a five-point Likert scale ranging from 1 (never) to 5 (very often). The survey comprised two subscales "loss of control/time management" (LoC; Cronbach's $\alpha \quad 0.865$ ) and "craving/social problems" (craving; Cronbach's $\alpha$.783), each comprising six items. The overall sum score could reach values between 12 and 60, with scores above 30 indicating being at risk and scores above 37 indicating problematic use (Pawlikowski et al., 2013). For this study, we used the sum scores of the two subscales to form a latent variable in the structural equation model.

\subsection{Statistical analyses}

Descriptive statistics and correlation analyses, namely, bivariate Pearson correlations, were calculated using SPSS 24.0 (IBM, 2016). CFA and structural equation modeling were conducted using Mplus 6 (Muthen \& Muthen, 2011). In addition to the $\chi^{2}$ test of model fit, we used the RMSEA, the CFI, the TLI, and the SRMR to evaluate the model. As Hu and Bentler (1999) recommend, an RMSEA no greater than 0.06, a CFI and TLI above 0.95, and SRMR values less than 0.08 indicate adequate model fit. For the structural equation model, we used item parceling (Little, Cunningham, Shahar, \& Widaman, 2002) to model each construct on a latent level (for a discussion about the use of parcels versus item-level responses see e.g. Little, Rhemtulla, Gibson, \& Schoemann, 2013). The item parcels were built according to the factors reported for the respective scale. For maximization (where the scale had no pre-defined subscales), we built three item parcels based on the scale's three dimensional structure, identified by Nenkov, Morrin, Schwartz, Ward, and Hulland (2008), with the dimensions named alternative search (items 1 to 6, Cronbach's $\alpha$ 0.551), decision difficulty (items 7 to 10, Cronbach's $\alpha$ 0.537), and high standards (items 11 to 13, Cronbach's $\alpha$ 0.617). For state FoMO (which already depicts one factor of the FoMO scale), we built two random item parcels (state FoMO $\begin{array}{lll}1 \text { : Cronbach's } \alpha & 0.720 \text {; state FoMO 2: Cronbach's } \alpha & 0.699) \text {. The }\end{array}$ model was analyzed using the MLMV estimator, as Maydeu-Olivares (2017) recommends. Data was complete. Bootstrapping was not applied.

\section{Results}

\subsection{Description and correlations}

Means, standard deviations, and bivariate correlations of the measures of maximization, procrastination, state FoMO, social zapping, and problematic social networks use are shown in Table 2. The mean sIAT_SNS sum score indicating tendencies toward problematic social 
Table 2

Descriptive statistics and correlations between the measures of maximization, procrastination, FoMO, social zapping, and problematic social networks use.

\begin{tabular}{|c|c|c|c|c|c|c|c|c|c|c|c|c|c|c|}
\hline & & $M$ & SD & 2 & 3 & 4 & 5 & 6 & 7 & 8 & 9 & 10 & 11 & 12 \\
\hline 1 & Maximization (mean) & 4.66 & 1.20 & $.338^{* *}$ & $.246^{* *}$ & $.248^{* *}$ & $.307^{* * *}$ & $.305^{* *}$ & $.280^{* * *}$ & $.296^{* *}$ & $.337^{* *}$ & $.261^{* *}$ & $.296^{* *}$ & $.302^{* *}$ \\
\hline 2 & PPS decisional & 2.77 & 0.94 & - & $.667^{* *}$ & $.560 * *$ & $.816^{* * *}$ & $.254 * *$ & $.359^{* *}$ & $.207 * *$ & $.323^{* *}$ & $.367 * *$ & $.373^{* *}$ & $.404 * *$ \\
\hline 3 & PPS behavioral & 3.05 & 1.07 & & - & $.646^{* *}$ & $.928^{* * *}$ & $.277^{* *}$ & $.259 * *$ & .128 & $.220 * *$ & $.434 * *$ & $.338^{* *}$ & .430 ** \\
\hline 4 & PPS timeliness & 2.31 & 0.91 & & & - & $.840 * *$ & $.238^{* *}$ & $.369^{* *}$ & $.165^{*}$ & $.301 * *$ & $.381^{* *}$ & $.365^{* *}$ & $.410^{* *}$ \\
\hline 5 & PPS overall (mean) & 2.73 & 0.86 & & & & - & $.297^{* *}$ & $.363^{* *}$ & $.181 * *$ & $.308^{* *}$ & $.460 * *$ & $.406^{* *}$ & $.478^{* *}$ \\
\hline 6 & State FoMO (mean) & 2.28 & 0.74 & & & & & - & $.178^{* *}$ & $.260 * *$ & $.260 * *$ & $.443 * *$ & $.481^{* *}$ & $.503^{* *}$ \\
\hline 7 & SZS behavioral & 1.94 & 0.86 & & & & & & - & $.467^{* *}$ & $.830 * *$ & $.266^{* *}$ & $.347^{* *}$ & $.329^{* *}$ \\
\hline 8 & SZS intentional & 2.14 & 1.01 & & & & & & & - & $.881 * *$ & $.251^{* *}$ & $.271^{* *}$ & $.284^{* *}$ \\
\hline 9 & SZS overall (mean) & 2.04 & 0.80 & & & & & & & & - & $.301^{* *}$ & $.357 * *$ & $.355^{* *}$ \\
\hline 10 & SIAT_SNS LoC & 16.54 & 5.26 & & & & & & & & & - & $.664 * *$ & $.938^{* *}$ \\
\hline 11 & sIAT_SNS craving & 10.69 & 3.88 & & & & & & & & & & - & $.882^{* *}$ \\
\hline 12 & sIAT_SNS overall (sum) & 27.24 & 8.35 & & & & & & & & & & & - \\
\hline
\end{tabular}

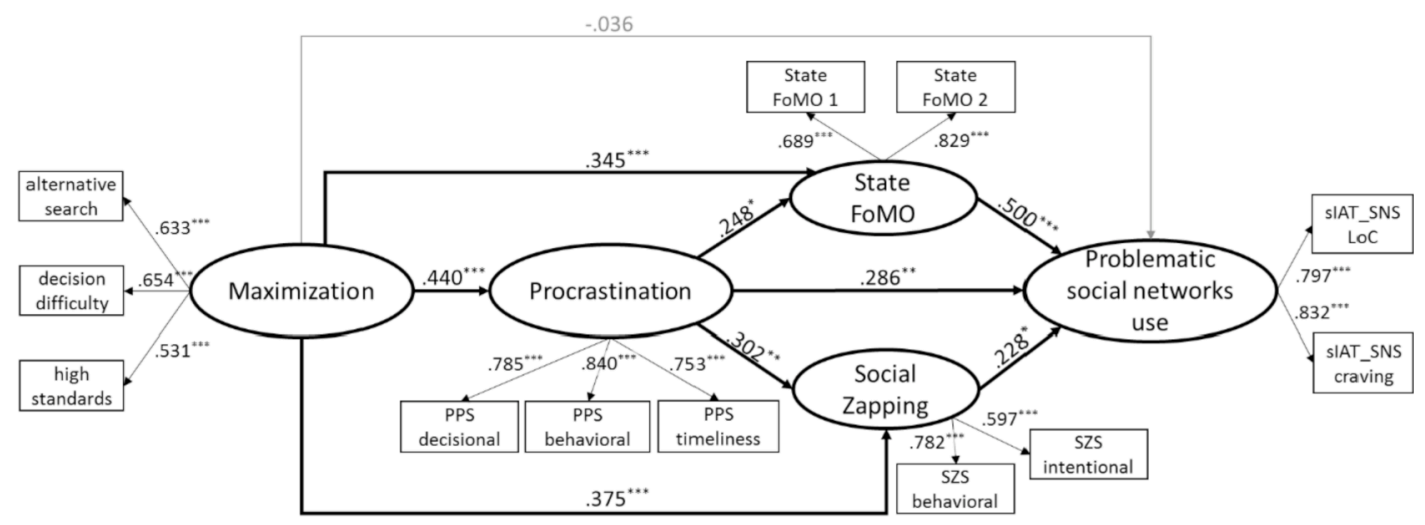

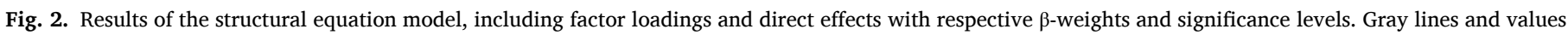

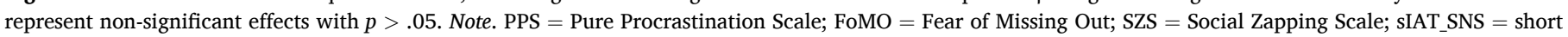
Internet Addiction Test specified for social networking sites; LoC Loss of control; ***p $\quad .001,{ }^{* * p} \quad .01,{ }^{*} p \quad .05$.

Table 3

Statistics of specific indirect effects in the structural equation model.

\begin{tabular}{|c|c|c|c|c|c|}
\hline \multicolumn{3}{|c|}{ Specific indirect effects } & \multirow[b]{2}{*}{$\beta$} & \multirow[b]{2}{*}{ S.E. } & \multirow[b]{2}{*}{$p$} \\
\hline Predictor & Mediator(s) & DV & & & \\
\hline Procr. & State FoMO & SIAT_SNS & .124 & .061 & .041 \\
\hline Procr. & Social zapping & sIAT_SNS & .069 & .042 & .105 \\
\hline Max. & Procr. & sIAT_SNS & .126 & .046 & .006 \\
\hline Max. & State FoMO & sIAT_SNS & .172 & .062 & .005 \\
\hline Max. & Social zapping & SIAT_SNS & .085 & .045 & .056 \\
\hline Max. & Procr., state FoMO & sIAT_SNS & .054 & .026 & .038 \\
\hline Max. & Procr., social zapping & SIAT_SNS & .030 & .019 & .114 \\
\hline Max. & Procr. & State FoMO & .109 & .045 & .015 \\
\hline Max. & Procr. & Social zapping & .133 & .044 & .003 \\
\hline
\end{tabular}

Note. DV dependent variable; Procr. Procrastination; FoMO Fear of Missing Out; Max. Maximization; sIAT_SNS short Internet Addiction Test specified for social networking sites.

networks use in the current sample is slightly higher compared with those reported in the literature that has used the same scale in nonclinical samples (Wegmann \& Brand, 2016; Wegmann et al., 2017). Nearly all correlations between the constructs are significant with low to moderate positive effect sizes. Accordingly, the preconditions for calculating the structural equation model are fulfilled.

Note. PPS Pure Procrastination Scale; FoMO Fear of Missing Out; SZS Social Zapping Scale; sIAT_SNS short Internet Addiction Test specified for social networking sites; LoC Loss of control; ${ }^{*} p \quad .050$, $\approx * p \quad .010$.

\subsection{Structural equation model}

The statistical model uses latent variables. Procrastination, social zapping, and problematic social networks use are represented as latent variables, based on the sub scores of the respective scales. Maximization and state FoMO are modeled using item parcels as manifest variables. The results indicate an acceptable model fit. The $\chi^{2} / \mathrm{df}$ is 1.46 , the RMSEA is 0.045 , the CFI is 0.968 , the TLI is 0.953 , and the SRMR is 0.043 . Overall, the model accounts for over half the variance in problematic social networks use, $R^{2} \quad 0.593, p<.001$. Fig. 2 illustrates the model results with respective values for factor loadings and direct effects. The results of the indirect effects are listed in Table 3.

Both state FoMO and social zapping have direct effects on the tendency toward problematic social networks use. Additionally, procrastination has a direct effect on problematic social networks use, state FoMO, and social zapping (Fig. 2). Furthermore, both state FoMO and social zapping partially mediate the effect of procrastination on problematic social networks use (Table 3). Maximization also has direct effects on state FoMO and social zapping and (to the greatest extent) on procrastination (Fig. 2). Within the model, there is no direct association between maximization and problematic social networks use (Fig. 2), but this effect is fully mediated by procrastination and by state FoMO (Table 3). Furthermore, the indirect effects of the paths from maximization over procrastination and, respectively, (a) FoMO and (b) social zapping on problematic social networks use are significant, but of relatively low sizes (Table 3 ). Additionally, procrastination mediates the effect of maximization on both FoMO $\left(R^{2} \quad 0.150, p<.01\right)$ and social zapping $\left(R^{2} \quad 0.279, p<.001\right)$.

\section{Discussion}

This study analyzed relationships between the tendencies to maximize decision outcomes (maximization), to delay tasks and decisions (procrastination), to fear to missing out when being online (state FoMO), 
to switch or cancel social appointments at the last minute (social zapping), and to use social networks problematically. The results revealed positive associations between the mentioned constructs. Furthermore, using structural equation modeling, we showed that social zapping and especially state FoMO mediate the effects of maximization and procrastination tendencies on problematic social networks use.

The results indicate that a higher tendency to procrastinate to find potentially "better" options is associated with a more problematic use of social networks. This finding adds to prior findings that high maximization tendencies are associated with negative social and psychological outcomes (Bruine de Bruin, Dombrovski, Parker, \& Szanto, 2016; Newman et al., 2018). We can also interpret the findings in the context of studies that have demonstrated that SNSs and other online media provide tools for (dysfunctional) procrastination behavior (Reinecke et al., 2018) and that procrastination is associated with problematic SNS use (Przepiorka et al., 2016) by revealing direct and indirect effects of procrastination on problematic social networks use. Results from our structural equation modeling show that the direct association between maximization and problematic social networks use was fully mediated by procrastination. This finding might indicate that the motivation to maximize decision outcomes increases the likelihood of procrastination, which then increases the risk for dysfunctional SNS use and dysfunctional online social interaction.

We assume that the special characteristics of SNSs and online communication provide a breeding ground for social comparison processes, which may increase feelings of FoMO (Milyavskaya et al., 2018). Further, the assumption that FoMO is linked to uncertainty about the "best" choice and to regret about potentially better options (Milyavskaya et al., 2018) is supported by the results of this study: We observed positive associations between FoMO and maximization. In addition to many options, SNSs, at the same time, offer an easy means to change decisions and search for alternatives. These opportunities may lead individuals, especially those who tend to procrastinate, to search for better options (e.g., Social Zappers) and use SNSs with increasing frequency. Thereby, using SNSs for the continuous search of social experiences that are better - or not worse - compared with the experiences of others may not lead to the desired gratification. By contrast, the behavior may be used to cope with unfulfilled needs or negative emotions - a mechanism characteristic of the development of addictive behaviors (Brand et al., 2019). FoMO and the willingness to behave in a socially undesirable manner to not miss a potentially more valuable social option (social zapping) may further enhance the risk of experiencing negative consequences from extensive SNS use and thus increase tendencies toward problematic social networks use.

The hypothesized mediating roles of FoMO and social zapping in the prediction of problematic social networks use are partly supported by the results of the structural equation model. State FoMO mediated the effects of both maximization and procrastination, and social zapping mediated the effect of maximization on problematic social networks use but only to a low extent. Based on the findings, we assume that especially socially driven fear reinforces the effects of maximization and procrastination on problematic SNS use. The contribution of maximization and procrastination tendencies becomes especially problematic in cases where SNS-specific social mechanisms and tendencies are factors. We observe that online FoMO enhances the effects of maximization and procrastination tendencies on problematic SNS use, indicating that the concept of FoMO might imply a maximizing component in terms of a FoMO on something "better."

The literature has suggested that SNSs' easy access to socially relevant information promotes increasing social networks use despite emerging negative affect (Muise et al., 2009). Procrastinating on SNSs while searching for "the best" or potentially more valuable (social) options requires collecting information on other possibilities and being up-to-date, which increases the frequency of social networks use. The mediation effect of FoMO indicates that this tendency may especially result in problematic SNS use in a case where it is reinforced by the fear that others, in her or his absence, potentially engage in more valuable social experiences. SNS can further be used to counter this fear by checking even more extensively on the activities of others. This could result in a seemingly endless search process that could lead individuals to lose control over their social networks use and to continue searching despite experiencing negative consequences. Questioning whether there are better alternatives and whether an individual would miss something valuable leads to avoiding commitment to choices which would result in increased dissatisfaction (Sparks, Ehrlinger, \& Eibach, 2012). Accordingly, online-related FoMO and tendencies toward socially deviant behavior such as social zapping can be considered socially driven mechanisms that enhance the negative effects of maximization and procrastination tendencies for developing symptoms of problematic social networks use.

The specific cognitions behind online FoMO and potentially social zapping (which requires further research) may represent specific Internet-related expectancies, which according to the I-PACE model (Brand et al., 2019), have a mediating role and could thus make a difference between non-problematic/functional and problematic/dysfunctional use. For example, high procrastination and social zapping tendencies can lead to increased negative outcomes in daily life, such as conflict with friends, which produces even more problems to make decisions about and more procrastination. These specific cognitions including fear-driven social cognitions and cognitions related to a (dysfunctional) demand for maximizing (social) outcomes can be starting points for targeted interventions and prevention strategies.

Social zapping is an empirically unexplored phenomenon. However, we argue that such phenomena that potentially arise from new technologies and associated services and offer an abundance of options in several domains (e.g., online shopping or streaming providers) must be considered when investigating respective problematic behaviors. With this study, we aimed to introduce this new construct and to present the first data indicating that this tendency might be worth considering for investigation in further research on online communication and SNS use. As no validated measure existed, we proposed a six-item scale (SZS) to measure social zapping tendencies, which revealed a consistent pattern for a behavioral and an intentional sub facet of this construct in the current sample. Nevertheless, validation studies are necessary to draw conclusions on the scale's suitability and reliability.

The results of the correlational analyses indicate that social zapping differs from the concepts of maximization, procrastination, and FoMO but that they share some of the variance. The reported direct and indirect effects of maximization and procrastination on social zapping indicate that continuously striving for the best choice through procrastinating on decisions can predict dysfunctional social behavior in terms of social zapping. This finding is in line with findings in the literature that have demonstrated that maximizing in the social domain can lead to negative affective outcomes (Newman et al., 2018). Further research is necessary to define the construct of social zapping more precisely and to validate the respective measure. Further, prospective studies should investigate the critical role of computer-mediated and online-based communication in the context of social zapping behavior. We assume that online communication through SNSs or other text-message-based applications (e.g., WhatsApp) can facilitate or maybe trigger socially deviant behavior such as social zapping because of its asynchronous and less intimate nature, which makes it easier to communicate non-binding statements or rejections because it can cause negative disinhibition effects (Suler, 2004). Thus, differences can be assumed between social zapping tendencies and are lived out online and offline.

Apart from short-term cancellations of appointments, it is reasonable that the seemingly endless process of searching, comparing, and adjusting social events, contacts, and status is a critical part when considering problematic SNS use (cf. Meier et al., 2016). Thereby, we can assume that many motivating factors play a role, for example, from narcissistic motives to deficits in self-confidence, for both of which associations with high SNS usage (Mehdizadeh, 2010) and with 
problematic use of social networks in specific and the internet in general have been demonstrated (Andreassen, Pallesen, \& Griffiths, 2017; Casale \& Fioravanti, 2018; Casale, Fioravanti, \& Rugai, 2016; Kircaburun \& Griffiths, 2018; Niemz, Griffiths, \& Banyard, 2005). FoMO likely plays a critical role in terms of a fear-driven reinforcing factor in this context (see also Wegmann \& Brand, 2019). Considering prevention and intervention, the strengthening of self-confidence may provide protection from problematic social networks use. Therefore, further research should investigate FoMO and other potentially mediating factors especially in relation to other predisposing and reinforcing variables to better understand underlying mechanisms of problematic social networks use, which is essential for deriving preventive measures.

A limitation of this study is that the construct and the scale for measuring social zapping are not validated. This study provided a first description and working definition of the construct and first data pointing at social zapping being a notable construct to study. However, the proposed construct must be validated and redefined if necessary on the basis of the results of further research. Furthermore, in addition to state FoMO, none of the measures of predictive variables was specifically framed on SNSs or online social interaction. The use of onlinespecific measures of procrastination, maximization, and social zapping, respectively, in comparison to general measures, would probably provide further insights into the importance of Internet-specific factors.

Notably, based on the current cross-sectional data, we cannot draw inferences on causality. For example, the causality of the association between high SNS use and high procrastination remains unclear. It is plausible that the frequent use of SNS and social media also facilitates procrastination. In a longitudinal study, Hinsch and Sheldon (2013) demonstrate that temporarily reducing or quitting the use of social online activities leads to decreased procrastination and increased life satisfaction. The authors conclude that heavy SNS users' increased procrastination is an effective coping tool for fulfilling the need of being socially connected but at the cost of the users' psychological well-being. Therefore and in accordance with others (e.g. Milyavskaya et al., 2018), we assume circular or bidirectional relationships in a manner that predictive variables, such as procrastination or FoMO, affect SNS use but that problematic SNS use, in turn, can affect these components with the progression of the problematic or addictive behavior in terms of stabilizing and intensifying mechanisms (cf. Brand et al., 2019).

\section{Conclusion}

Our findings suggest that maximization and procrastination tendencies gradually contribute to problematic use of social networks, especially if reinforced by specific fears or expectancies to perhaps miss out on something (more) valuable, as indicated by the mediating roles of FoMO and the tendency to spontaneously switch appointments. This has implications on the relevance of fear-related but also maximizing motives for a dysfunctional use of SNSs and online communication applications. We encourage further research to focus on specific socially driven affective and behavioral tendencies that may increase or decrease the detrimental effects of specific predisposing personality facets on social networks use and individual well-being.

\section{Declaration of competing interest}

The authors have no competing interests to declare.

\section{CRediT authorship contribution statement}

Silke M. Müller: Conceptualization, Methodology, Formal analysis, Writing - original draft, Writing - review \& editing, Visualization. Elisa Wegmann: Formal analysis, Validation, Writing - review \& editing. Dario Stolze: Conceptualization, Methodology, Investigation, Writing review \& editing. Matthias Brand: Supervision, Writing - review \& editing.

\section{References}

Andreassen, C. S., Pallesen, S., \& Griffiths, M. D. (2017). The relationship between addictive use of social media, narcissism, and self-esteem: Findings from a large national survey. Addictive Behaviors, 64, 287-293. https://doi.org/10.1016/j. addbeh.2016.03.006.

Appel, H., Gerlach, A. L., \& Crusius, J. (2016). The interplay between Facebook use, social comparison, envy, and depression. Current Opinion in Psychology, 9, 44-49. https://doi.org/10.1016/j.copsyc.2015.10.006.

Baker, L. R., \& Oswald, D. L. (2010). Shyness and online social networking services. Journal of Social and Personal Relationships, 27(7), 873-889. https://doi.org/ 10.1177/0265407510375261.

Bechara, A. (2005). Decision making, impulse control and loss of willpower to resist drugs: A neurocognitive perspective. Nature Neuroscience, 8(11), 1458-1463. https://doi.org/10.1038/nn1584.

Blanchard, A. L., \& Henle, C. A. (2008). Correlates of different forms of cyberloafing: The role of norms and external locus of control. Computers in Human Behavior, 24(3), 1067-1084. https://doi.org/10.1016/j.chb.2007.03.008.

Brand, M., Wegmann, E., Stark, R., Müller, A., Wolfling, K., Robbins, T. W., et al. (2019). The Interaction of Person-Affect-Cognition-Execution (I-PACE) model for addictive behaviors: Update, generalization to addictive behaviors beyond internet-use disorders, and specification of the process character of addictive behaviors. Neuroscience \& Biobehavioral Reviews, 104, 1-10. https://doi.org/10.1016/j. neubiorev.2019.06.032.

Brand, M., Young, K. S., Laier, C., Wolfling, K., \& Potenza, M. N. (2016). Integrating psychological and neurobiological considerations regarding the development and maintenance of specific Internet-use disorders: An Interaction of Person-AffectCognition-Execution (I-PACE) model. Neuroscience \& Biobehavioral Reviews, 71, 252-266. https://doi.org/10.1016/j.neubiorev.2016.08.033.

Bruine de Bruin, W., Dombrovski, A. Y., Parker, A. M., \& Szanto, K. (2016). Late-life depression, suicidal ideation, and attempted suicide: The role of individual differences in maximizing, regret, and negative decision outcomes. Journal of Behavioral Decision Making, 29(4), 363-371. https://doi.org/10.1002/bdm.1882.

Caplan, S. E. (2005). A social skill account of problematic Internet use. Journal of Communication, 55(4), 721-736. https://doi.org/10.1111/j.1460-2466.2005. tb03019.x.

Caplan, S. E. (2006). Relations among loneliness, social anxiety, and problematic Internet use. CyberPsychology and Behavior, 10(2), 234-242. https://doi.org/ 10.1089/cpb.2006.9963.

Casale, S., \& Fioravanti, G. (2018). Why narcissists are at risk for developing Facebook addiction: The need to be admired and the need to belong. Addictive Behaviors, 76, 312-318. https://doi.org/10.1016/j.addbeh.2017.08.038.

Casale, S., Fioravanti, G., \& Rugai, L. (2016). Grandiose and vulnerable narcissists: Who is at higher risk for social networking addiction? Cyberpsychology, Behavior, and Social Networking, 19(8), 510-515. https://doi.org/10.1089/cyber.2016.0189.

Cheek, N. N., \& Schwartz, B. (2016). On the meaning and measurement of maximization. Judgment and Decision Making, 11(2), 126-146.

Davis, R. A. (2001). A cognitive-behavioral model of pathological Internet use. Computers in Human Behavior, 17(2), 187-195. https://doi.org/10.1016/S0747-5632(00) 00041-8.

Davis, R. A., Flett, G. L., \& Besser, A. (2002). Validation of a new scale for measuring problematic Internet use: Implications for pre-employment screening. CyberPsychology and Behavior, 5(4), 331-345. https://doi.org/10.1089/ 109493102760275581.

Dempsey, A. E., O’Brien, K. D., Tiamiyu, M. F., \& Elhai, J. D. (2019). Fear of missing out (FoMO) and rumination mediate relations between social anxiety and problematic Facebook use. Addictive Behaviors Reports, 9, 100150. https://doi.org/10.1016/j. abrep.2018.100150.

Dienlin, T., Masur, P. K., \& Trepte, S. (2017). Reinforcement or displacement? The reciprocity of FTF, IM, and SNS communication and their effects on loneliness and life satisfaction. Journal of Computer-Mediated Communication, 22(2), 71-87. https:// doi.org/10.1111/jcc4.12183.

Ferrari, J. R. (2000). Procrastination and attention: Factor analysis of attention deficit, boredomness, intelligence, self-esteem, and task delay frequencies. Journal of Social Behavior \& Personality, 15(5), 185-196.

Ferrari, J. R., \& Dovidio, J. F. (2000). Examining behavioral processes in indecision: Decisional procrastination and decision-making style. Journal of Research in Personality, 34(1), 127-137. https://doi.org/10.1006/jrpe.1999.2247.

Frost, R. O., \& Shows, D. L. (1993). The nature and measurement of compulsive indecisiveness. Behaviour Research and Therapy, 31(7), 683-692. https://doi.org/ 10.1016/0005-7967(93)90121-A.

Geng, J., Han, L., Gao, F., Jou, M., \& Huang, C.-C. (2018). Internet addiction and procrastination among Chinese young adults: A moderated mediation model. Computers in Human Behavior, 84, 320-333. https://doi.org/10.1016/j. chb.2018.03.013.

Greifeneder, R., \& Betsch, C. (2006). Validation and German translation of the maximizing scale. Zeitschrift für Sozialpsychologie, 37(4), 233-243. https://doi.org/ 10.1024/0044-3514.37.4.233.

Griffiths, M. D., Kuss, D. J., \& Demetrovics, Z. (2014). Social networking addiction: An overview of preliminary findings. In K. P. Rosenberg, \& L. Curtiss Feder (Eds.), Behavioral addictions: Criteria, evidence, and treatment (pp. 119-141). New York, NY: Elsevier. 
Guedes, E., Nardi, A. E., Guimarães, F. M. C. L., Machado, S., \& King, A. L. S. (2016). Social networking, a new online addiction: A review of Facebook and other addiction disorders. Medical, 3, 1-6. https://doi.org/10.5935/MedicalExpress.2016.01.0.

Harriott, J. S., Ferrari, J. R., \& Dovidio, J. F. (1996). Distractibility, daydreaming, and self-critical cognitions as determinants of indecision. Journal of Social Behavior \& Personality, 11(2), 337-344.

Hinsch, C., \& Sheldon, K. M. (2013). The impact of frequent social Internet consumption: Increased procrastination and lower life satisfaction. Journal of Consumer Behaviour, 12(6), 496-505. https://doi.org/10.1002/cb.1453.

Ho, R. C., Zhang, M. W. B., Tsang, T. Y., Toh, A. H., Pan, F., Lu, Y., ... Lai, C.-M. (2014). The association between internet addiction and psychiatric co-morbidity: A metaanalysis. BMC Psychiatry, 14, 1-10.

Hu, L.t., \& Bentler, P. M. (1999). Cutoff criteria for fit indexes in covariance structure analysis: Conventional criteria versus new alternatives. Structural Equation Modeling: A Multidisciplinary Journal, 6(1), 1-55. https://doi.org/10.1080/ 10705519909540118.

IBM. (2016). IBM SPSS statistics for windows. Armonk, NY: IBM Corp Version 24.0. .

Iyengar, S. S., Wells, R. E., \& Schwartz, B. (2006). Doing better but feeling worse: Looking for the "best" job undermines satisfaction. Psychological Science, 17(2), 143-150. https://doi.org/10.1111/j.1467-9280.2006.01677.x.

Kim, J., Hong, H., Lee, J., \& Hyun, M.-H. (2017). Effects of time perspective and selfcontrol on procrastination and Internet addiction. Journal of Behavioral Addictions, 6 (2), 229-236. https://doi.org/10.1556/2006.6.2017.017.

Kircaburun, K., \& Griffiths, M. D. (2018). The dark side of internet: Preliminary evidence for the associations of dark personality traits with specific online activities and problematic internet use. Journal of Behavioral Addictions, 7(4), 993-1003. https:// doi.org/10.1556/2006.7.2018.109.

Kokkoris, M. D. (2019). Maximizing without borders: Evidence that maximizing transcends decision domains. Frontiers in Psychology, 9(2664), 1-6. https://doi.org/ 10.3389/fpsyg.2018.02664.

Kuss, D. J., \& Griffiths, M. D. (2011). Online social networking and addiction - a review of the psychological literature. International Journal of Environmental Research and Public Health, 8(9), 3528-3552. https://doi.org/10.3390/ijerph8093528.

Kuss, D. J., \& Griffiths, M. D. (2017). Social networking sites and addiction: Ten lessons learned. International Journal of Environmental Research and Public Health, 14(3), 311-328. https://doi.org/10.3390/ijerph14030311.

lastminutede. (2012). Social zapping neuer trend in europa: Mehr als jeder 2. Versetzt freunde und familie, wenn kurzfristig bessere alternativen winken. http://blog.last minute.de/social-zapping/.

LaRose, R., Lin, C. A., \& Eastin, M. S. (2003). Unregulated Internet usage: Addiction, habit, or deficient self-regulation? Media Psychology, 5(3), 225-253. https://doi.org/ 10.1207/S1532785XMEP0503_01.

Lavoie, J. A. A., \& Pychyl, T. A. (2001). Cyberslacking and the procrastination superhighway: A web-based survey of online procrastination, attitudes, and emotion. Social Science Computer Review, 19(4), 431-444. https://doi.org/10.1177/ 089443930101900403.

Lay, C. H. (1986). At last, my research article on procrastination. Journal of Research in Personality, 20(4), 474-495. https://doi.org/10.1016/0092-6566(86)90127-3.

Lay, C. H., \& Burns, P. (1991). Intention and behavior in studying for an examination: The role of triat procrastination and its interaction with optimism. Journal of Social Behavior \& Personality, 6(3), 605-617.

Little, T. D., Cunningham, W. A., Shahar, G., \& Widaman, K. F. (2002). To parcel or not to parcel: Exploring the question, weighing the merits. Structural Equation Modeling, 9 (2), 151-173. https://doi.org/10.1207/S15328007SEM0902 1.

Little, T. D., Rhemtulla, M., Gibson, K., \& Schoemann, A. M. (2013). Why the items versus parcels controversy needn't be one. Psychological Methods, 18(3), 285-300. https://doi.org/10.1037/a0033266.

Mann, L., Burnett, P., Radford, M., \& Ford, S. (1997). The Melbourne Decision Making Questionnaire: An instrument for measuring patterns for coping with decisional conflict. Journal of Behavioral Decision Making, 10(1), 1-19. https://doi.org/ 10.1002/(SICI)1099-0771(199703)10:1<1::AID-BDM242>3.0.CO;2-X.

Maydeu-Olivares, A. (2017). Maximum likelihood estimation of structural equation models for continuous data: Standard errors and goodness of fit. Structural Equation Modeling: A Multidisciplinary Journal, 24(3), 383-394. https://doi.org/10.1080/ 10705511.2016.1269606.

McCown, W., Johnson, J., \& Petzel, T. (1989). Procrastination, a principal components analysis. Personality and Individual Differences, 10(2), 197-202. https://doi.org/ 10.1016/0191-8869(89)90204-3.

Mehdizadeh, S. (2010). Self-presentation 2.0: Narcissism and self-esteem on Facebook. Cyberpsychology, Behavior, and Social Networking, 13(4), 357-364. https://doi.org/ 10.1089/cpb.2008.0263.

Meier, A., Reinecke, L., \& Meltzer, C. E. (2016). "Facebocrastination"? Predictors of using Facebook for procrastination and its effects on students' well-being. Computers in Human Behavior, 64, 65-76. https://doi.org/10.1016/j.chb.2016.06.011.

Mikkelson, A. C., \& Pauley, P. M. (2013). Maximizing relationship possibilities: Relational maximization in romantic relationships. The Journal of Social Psychology, 153(4), 467-485. https://doi.org/10.1080/00224545.2013.767776.

Milyavskaya, M., Saffran, M., Hope, N., \& Koestner, R. (2018). Fear of missing out: Prevalence, dynamics, and consequences of experiencing FOMO. Motivation and Emotion, 42(5), 725-737. https://doi.org/10.1007/s11031-018-9683-5.

Misuraca, R., \& Fasolo, B. (2018). Maximizing versus satisficing in the digital age: Disjoint scales and the case for "construct consensus". Personality and Individual Differences, 121, 152-160. https://doi.org/10.1016/j.paid.2017.09.031.

Montag, C., Zhao, Z., Sindermann, C., Xu, L., Fu, M., Li, J., ... Becker, B. (2018). Internet communication disorder and the structure of the human brain: Initial insights on
WeChat addiction. Scientific Reports, 8(1), 1-10. https://doi.org/10.1038/s41598018-19904-y.

Muise, A., Christofides, E., \& Desmarais, S. (2009). More information than you ever wanted: Does Facebook bring out the green-eyed monster of jealousy? CyberPsychology and Behavior, 12(4), 441-444. https://doi.org/10.1089/ cpb.2008.0263.

Muthen, L. K., \& Muthen, B. O. (2011). Mplus (Version 6) [computer software]. Los Angeles: Muthen and Muthen.

Nenkov, G. Y., Morrin, M., Schwartz, B., Ward, A., \& Hulland, J. (2008). A short form of the Maximization Scale: Factor structure, reliability and validity studies. Judgment and Decision Making, 3(5), 371-388.

Newman, D. B., Schug, J., Yuki, M., Yamada, J., \& Nezlek, J. B. (2018). The negative consequences of maximizing in friendship selection. Journal of Personality and Social Psychology, 114(5), 804-824. https://doi.org/10.1037/pspp0000141.

Niemz, K., Griffiths, M., \& Banyard, P. (2005). Prevalence of pathological Internet use among university students and correlations with self-esteem, the General Health Questionnaire (GHQ), and disinhibition. CyberPsychology and Behavior, 8(6), 562-570. https://doi.org/10.1089/cpb.2005.8.562.

Oberst, U., Wegmann, E., Stodt, B., Brand, M., \& Chamarro, A. (2017). Negative consequences from heavy social networking in adolescents: The mediating role of fear of missing out. Journal of Adolescence, 55, 51-60. https://doi.org/10.1016/j. adolescence.2016.12.008.

Orr, E. S., Sisic, M., Ross, C., Simmering, M. G., Arseneault, J. M., \& Orr, R. R. (2009). The influence of shyness on the use of Facebook in an undergraduate sample. CyberPsychology and Behavior, 12(3), 337-340. https://doi.org/10.1089/ cpb.2008.0214.

Parker, A. M., Bruine de Bruin, W., \& Fischhoff, B. (2007). Maximizers versus satisficers: Decision-making styles, competence, and outcomes. Judgment and Decision Making, 2 (6), 342-350.

Patchin, J. W., \& Hinduja, S. (2006). Bullies move beyond the schoolyard: A preliminary look at cyberbullying. Youth Violence and Juvenile Justice, 4(2), 148-169. https://doi. org $/ 10.1177 / 1541204006286288$.

Pawlikowski, M., Altstotter-Gleich, C., \& Brand, M. (2013). Validation and psychometric properties of a short version of Young's Internet Addiction Test. Computers in Human Behavior, 29, 1212-1223. https://doi.org/10.1016/j.chb.2012.10.014.

Pierce, T. (2009). Social anxiety and technology: Face-to-face communication versus technological communication among teens. Computers in Human Behavior, 25(6), 1367-1372. https://doi.org/10.1016/j.chb.2009.06.003.

Przepiorka, A., Błachnio, A., \& Díaz-Morales, J. F. (2016). Problematic Facebook use and procrastination. Computers in Human Behavior, 65, 59-64. https://doi.org/10.1016/j. chb.2016.08.022.

Przybylski, A. K., Murayama, K., DeHaan, C. R., \& Gladwell, V. (2013). Motivational, emotional, and behavioral correlates of fear of missing out. Computers in Human Behavior, 29(4), 1841-1848. https://doi.org/10.1016/j.chb.2013.02.014.

Pychyl, T. A., Morin, R. W., \& Salmon, B. R. (2000). Procrastination and the planning fallacy: An examination of the study habits of university students. Journal of Social Behavior \& Personality, 15(5), 135-150.

Rassin, E., \& Muris, P. (2005). To be or not to be... indecisive: Gender differences, correlations with obsessive-compulsive complaints, and behavioural manifestation. Personality and Individual Differences, 38(5), 1175-1181. https://doi.org/10.1016/j. paid.2004.07.014.

Rassin, E., Muris, P., Franken, I., Smit, M., \& Wong, M. (2007). Measuring general indecisiveness. Journal of Psychopathology and Behavioral Assessment, 29(1), 60-67. https://doi.org/10.1007/s10862-006-9023-z.

Reinecke, L., Meier, A., Aufenanger, S., Beutel, M. E., Dreier, M., Quiring, O., Müller, K. W. (2018). Permanently online and permanently procrastinating? The mediating role of internet use for the effects of trait procrastination on psychological health and well-being. 20 pp. 862-880). New Media \& Society. https://doi.org/10.1177/ 1461444816675437, 3.

Reinecke, L., Vorderer, P., \& Knop, K. (2014). Entertainment 2.0? The role of intrinsic and extrinsic need satisfaction for the enjoyment of Facebook use. Journal of Communication, 64(3), 417-438. https://doi.org/10.1111/jcom.12099.

Rozgonjuk, D., Kattago, M., \& Taht, K. (2018). Social media use in lectures mediates the relationship between procrastination and problematic smartphone use. Computers in Human Behavior, 89, 191-198. https://doi.org/10.1016/j.chb.2018.08.003.

Ryan, T., Chester, A., Reece, J., \& Xenos, S. (2014). The uses and abuses of Facebook: A review of Facebook addiction. Journal of Behavioral Addictions, 3(3), 133-148. https://doi.org/10.1556/JBA.3.2014.016.

Salehan, M., \& Negahban, A. (2013). Social networking on smartphones: When mobile phones become addictive. Computers in Human Behavior, 29(6), 2632-2639. https:// doi.org/10.1016/j.chb.2013.07.003.

Schwartz, B., Ward, A., Monterosso, J., Lyubomirsky, S., White, K., \& Lehman, D. R. (2002). Maximizing versus satisficing: Happiness is a matter of choice. Journal of Personality and Social Psychology, 83(5), 1178-1197. https://doi.org/10.1037/00223514.83.5.1178.

Sirois, F. M. (2014). Out of sight, out of time? A meta-analytic investigation of procrastination and time perspective. European Journal of Personality, 28(5), 511-520. https://doi.org/10.1002/per.1947.

Slonje, R., \& Smith, P. K. (2008). Cyberbullying: Another main type of bullying? Scandinavian Journal of Psychology, 49(2), 147-154. https://doi.org/10.1111/ j.1467-9450.2007.00611.x.

Sparks, E. A., Ehrlinger, J., \& Eibach, R. P. (2012). Failing to commit: Maximizers avoid commitment in a way that contributes to reduced satisfaction. Personality and Individual Differences, 52(1), 72-77. https://doi.org/10.1016/j.paid.2011.09.002. 
Spunt, R. P., Rassin, E., \& Epstein, L. M. (2009). Aversive and avoidant indecisiveness: Roles for regret proneness, maximization, and BIS/BAS sensitivities. Personality and Individual Differences, 47(4), 256-261. https://doi.org/10.1016/j.paid.2009.03.009.

Steel, P. (2010). Arousal, avoidant and decisional procrastinators: Do they exist? Personality and Individual Differences, 48(8), 926-934. https://doi.org/10.1016/j. paid.2010.02.025.

Suler, J. (2004). The online disinhibition effect. CyberPsychology and Behavior, 7(3), 321-326. https://doi.org/10.1089/1094931041291295.

Svartdal, F., Pfuhl, G., Nordby, K., Foschi, G., Klingsieck, K. B., Rozental, A., ... Rębkowska, K. (2016). On the measurement of procrastination: Comparing two scales in six European countries. Frontiers in Psychology, 7(1307), 1-11. https://doi org/10.3389/fpsyg.2016.01307.

Svartdal, F., \& Steel, P. (2017). Irrational delay revisited: Examining five procrastination scales in a global sample. Frontiers in Psychology, 8(1927), 1-10. https://doi.org/ 10.3389/fpsyg.2017.01927.

Tuckman, B. W. (1991). The development and concurrent validity of the procrastination scale. Educational and Psychological Measurement, 51(2), 473-480. https://doi.org/ $10.1177 / 0013164491512022$.

Turner, B. M., Rim, H. B., Betz, N. E., \& Nygren, T. E. (2012). The maximization inventory. Judgment and Decision Making, 7(1), 48-60.

Verduyn, P., Lee, D. S., Park, J., Shablack, H., Orvell, A., Bayer, J., ... Kross, E. (2015) Passive Facebook usage undermines affective well-being: Experimental and longitudinal evidence. Journal of Experimental Psychology: General, 144(2), 480-488. https://doi.org/10.1037/xge0000057.

Wallace, L., James, T. L., \& Warkentin, M. (2017). How do you feel about your friends? Understanding situational envy in online social networks. Information \& Management, 54(5), 669-682. https://doi.org/10.1016/j.im.2016.12.010.

Wegmann, E., \& Brand, M. (2016). Internet-communication disorder: It's a matter of social aspects, coping, and Internet-use expectancies. Frontiers in Psychology, 7 (1747), 1-14. https://doi.org/10.3389/fpsyg.2016.01747.
Wegmann, E., \& Brand, M. (2019). A narrative overview about psychosocial characteristics as risk factors of a problematic social-networks use. Current Addiction Reports, 6(4), 402-409. https://doi.org/10.1007/s40429-019-00286-8.

Wegmann, E., Müller, S. M., Ostendorf, S., \& Brand, M. (2018). Highlighting Internetcommunication disorder as further Internet-use disorder when considering neuroimaging studies. Current Behavioral Neuroscience Reports, 5(4), 295-301. https://doi.org/10.1007/s40473-018-0164-7.

Wegmann, E., Oberst, U., Stodt, B., \& Brand, M. (2017). Online-specific fear of missing out and Internet-use expectancies contribute to symptoms of Internetcommunication disorder. Addictive Behaviors Reports, 5, 33-42. https://doi.org/ 10.1016/j.abrep.2017.04.001.

Wegmann, E., Stodt, B., \& Brand, M. (2015). Addictive use of social networking sites can be explained by the interaction of Internet use expectancies, Internet literacy, and psychopathological symptoms. Journal of Behavioral Addictions, 4(3), 155-162. https://doi.org/10.1556/2006.4.2015.021.

Wolak, J., Mitchell, K. J., \& Finkelhor, D. (2007). Does online harassment constitute bullying? An exploration of online harassment by known peers and online-only contacts. Journal of Adolescent Health, 41(6), S51-S58. https://doi.org/10.1016/j. jadohealth.2007.08.019.

Wolniewicz, C. A., Rozgonjuk, D., \& Elhai, J. D. (2019). Boredom proneness and fear of missing out mediate relations between depression and anxiety with problematic smartphone use. Human Behavior and Emerging Technologies, 1-10. https://doi.org/ 10.1002/hbe2.159.

World Health Organization. (2019). International classification of diseases 11th revision. Retrieved from https://icd.who.int.

Zap. (n.d.). In The Merriam-Webster.com Dictionary. Retrieved January 13, 2020, from https://www.merriam-webster.com/dictionary/zapping. 


\section{DuEPublico}

Duisburg-Essen Publications online

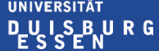

offen im Denken

Ub $\mid \begin{aligned} & \text { universitäts } \\ & \text { bibliothek }\end{aligned}$

This text is made available via DuEPublico, the institutional repository of the University of Duisburg-Essen. This version may eventually differ from another version distributed by a commercial publisher.

DOI: $\quad 10.1016 /$ j.chb.2020.106296

URN: urn:nbn:de:hbz:464-20200214-134837-2

This work may be used under a Creative Commons Attribution -

NonCommercial - NoDerivatives 4.0 License (CC BY-NC-ND 4.0) 